Paediatric Psychology

\title{
Consequences of Child Abuse and Neglect
}

\author{
Arta Dodaj ${ }^{1}$ Kristina Sesar ${ }^{2}$ \\ ${ }^{1}$ University of Zadar, Zadar, Croatia, ${ }^{2}$ University of Mostar, Mostar, Bosnia and Herzegovina
}

Correspondence: artadodaj@gmail.com; Tel.: +385 98800 187; Fax.: +38523200625

Received: November 13, 2019; Accepted: January 30, 2020

\begin{abstract}
The aim of this article is to present a review of the research surrounding the short-term and long-term psychological and health consequences of child abuse and neglect. Research papers related to the consequences of child abuse and neglect and published in leading academic journals were identified and reviewed. We found that most of the available research suggests that there is a variety of negative outcomes among those exposed to physical, sexual and emotional abuse, neglect, witnessing domestic violence and multi-type childhood abuse. Specifically, there was evidence of significant short-term and long-term consequences encompassing physical and mental health difficulties, subsequent perpetrations, social and cognitive difficulties, and attachment. Conclusion - The results of this review confirm that there is a wide range of short-term and long-term difficulties that are associated with child abuse and neglect. This variety of difficulties should be taken into account in approaching complex and multidisciplinary assessment and treatment.
\end{abstract}

Key Words: Childhood Abuse and Neglect - Multi-Type Childhood Abuse - Physical and Psychological Difficulties - Subsequent Perpetration - Social Difficulties - Cognitive Difficulties.

\section{Introduction}

Childhood abuse is defined as physical, sexual or emotional abuse, neglect or exploitation of a child resulting in real or potential harm to the child's health, survival, development or dignity (1). In recent years, witnessing domestic abuse (WDV) has been recognized as a form of abusive behavior that has a significant effect on the health and safety of a child, but also their psychological adjustment (2). Concern about the possible negative effects of child abuse and neglect is probably the main reason for the rise in research interest in this field.

Reactions to a negative event, such as exposure to different forms of abuse and neglect, include excessive arousal and sensitivity of the limbic system (3). Strong, frequent, or prolonged activation of a person's stress response system, often-referred to as toxic stress, can have long-lasting damaging effects on an individual's health, behaviour, and ability to learn. It can change an individual's brain architecture, which can cause the person's stress response system to be triggered more frequently and for longer periods, and place him or her at increased risk for a variety of physical and mental health problems. Children who experience early life toxic stress are at risk of long-term adverse health effects that may not manifest until adulthood (4). However, reactions to abuse and neglect are very individual. One person may have several mild symptoms, whilst another victim may show symptoms in several fields of functioning throughout their entire life. The consequences of abuse and neglect may be short-term and long-term, and they are most often divided into several different and overlapping categories: physical and mental health difficulties, subsequent perpetrations, and social and cognitive difficulties. 
The aim of this study was to review the consequences of child abuse and neglect, based on a review of papers published to date in this field.

\section{Consequences of Childhood Physical Abuse}

Self-reported physical abuse in childhood increases the likelihood of reporting more diagnosed illnesses and physical symptoms nearly 40 years after the abuse took place (5). There is suggestive evidence of a significant association between child physical abuse (CPA) and arthritis, ulcers, and headache/ migraine in adulthood. For other outcomes, including type 2 diabetes, hypertension, cardiovascular diseases, respiratory diseases, neurological disorders, and cancer, the association is mostly weak and inconsistent (6).

In children who were physically abused in childhood, changes were found in the size of the hypocampus (reduction). They had electro-physiological abnormalities in the frontotemporal and anterior regions of the brain, cerebral atrophy, cerebral ischaemia and hormonal changes (increase cortisol levels) (7-11). Furthermore, they had changes in sleep rhythms (increased activity during sleep and prolonged latent sleep) and a lower pain threshold (12).

CPA is considered to be a modifiable risk factor for mental disorders throughout life. The overview of the evidence suggests a causal relationship between CPA and a range of long-term consequences such as: depressive disorders, anxiety disorders and suicidal behaviour (6). Physically abused children often experience so-called dysphoria - a state of confusion, emptiness, internal solitude and unease (13). Studies have found a significant correlation between CPA and the risk of suicidal behaviour, especially during adolescence and young adulthood (14). Eating disorders, such as anorexia nervosa and bulimia, also may be connected to CPA (15).

Results to date show that infants and small children exposed to CPA have an increased risk of developing insecure or disorganized attachments with their primary care-givers, in comparison to children who have not had the experience of CPA
(3, 16). Forms of attachment are extremely important for a child's emotional and social development. For children with insecure attachment, the parent/guardian (who should be the primary source of security and protection) becomes a source of fear and danger, and brings the child into a conflict that they cannot resolve (16). Without security and support from the primary caregiver, infants and children may have difficulties in developing trust in other people in stressful situations, which may then lead to the constant presence of a feeling of fear and anxiety (3). Uncertain attachment hinders the child's normal developmental process, which may then result in the child having difficulties in communication with peers during childhood and adolescence, and in adulthood difficulties in establishing and maintaining healthy partner relationships throughout life (17).

CPA may lead to consumption of alcohol and other psychoactive substances (18), narcotics and cigarettes in adolescence (19). Children exposed to CPA are more prone to inflict pain on others (17, 20). Research shows that exposure to CPA is one of the most consistent predictors of juvenile aggressive and criminal behaviour $(20,21)$. The study findings indicate that being physically abused during childhood has strong independent effects on an individual's likelihood of becoming a victim of intimate partner violence (IPV), general violence, or both, in early adulthood (22). Lower levels of motivation, poor success in school and premature ending of education are consequences of CPA (23).

\section{Consequences of Childhood Emotional}

\section{Abuse}

Childhood emotional abuse (CEA) increases the risk of physical health problems, such as ischemic heart disease, Type 2 diabetes, ulcers, headache and migraine in adulthood $(6,24)$. Further, research shows that people exposed to CEA are at greater risk of developing infectious illnesses, lung diseases and neurological ailments in adulthood, and to contracting oncological diseases $(24,25)$. Anxiety and depression in adulthood are very frequent 
consequences of exposure to this form of CEA (6, 26). Children and adults with experience of CEA have a much higher risk of committing suicide or having suicidal thoughts than the control group (6, 14, 27). Jeon et al. (27) state that, of the different forms of CEA, the one related to an emotionally cold parental approach is more strongly related to suicidal behaviour than the approach where parents do not understand, ignore or mock their child's needs. According to the Adverse Childhood Experience Longitudinal Study, the most prominent consequences are the development of psychiatric disorders (28). Some evidence concerning the potentially differential (unique) effects of CEA in childhood emerged in the finding that CEA was the strongest and most consistent predictor of internalizing problems (e.g., depression, GAD, SAD, attachment problems) in children and adolescents (29). CEA was also the strongest predictor of substance abuse-raising the question as to whether substance abuse may serve as an associated coping mechanism and "cascading" secondary outcome $(29,30)$. These findings are consistent with earlier research linking CEA to a range of internalizing symptoms, relational insecurity, and negative selfperceptions (e.g. 29, 31). Furthermore, CEA is a strong predictor of externalizing problems (e.g., behavioural problems, self-injury, criminal activity) in children and adolescents (29). Children or adults exposed to CEA are at greater risk of obesity (6) and eating disorders (32). Studies have also linked CEA with maladjusted sexual behaviour (33). Persons exposed to CEA have a significantly higher risk of smoking, and consumption of alcohol and other psychoactive substances (6).

\section{Consequences of Childhood Sexual Abuse}

Exposure to childhood sexual abuse (CSA) may result in short and long-term health impairments (34). According to the results of Hinchliffe's research (35) 65\% of injuries to children exposed to CSA are found on the head, neck or mouth. A meta-analytic review conducted by Irish et al. (36) highlighted the long-term physical health conse- quences of CSA. The results of the present metaanalysis support the conclusions of many qualitative reviews (e.g., 37), demonstrating that CSA is systematically related to higher rates of subsequent physical health symptoms, including general health, gynaecological, pain and cardiopulmonary symptoms, obesity, and autoimmune disorders (irritable bowel syndrome, asthma, fibromyalgia). Women exposed to CSA are at greater risk of contracting sexually transmitted diseases or being HIV positive, in comparison to women without a history of CSA (38).

Studies have reported associations between CSA and mental health disorders (39-42). Certain characteristics of CSA are related to a greater risk of mental health problems, such as the age of onset of abuse, a higher number of incidents of abuse, a higher number of abusers and penetration, and sexual abuse in later life (43). Adults with a history of CSA have 2.4 times more likelihood of developing mental health disorders than adults who did not have that experience (44). It has been shown that in patients suffering from depression who were exposed to CSA, depressive episodes last longer than in patients who were not sexually abused (45). Adults with major depression who experienced CSA had poorer response outcomes to antidepressant treatment, especially if the maltreatment occurred when they were aged 7 or younger (46).

CSA is a well-known risk for suicidal behaviour in childhood and in adulthood (47-50). The earlier the age at onset of CSA, the greater suicidal intent reported for suicide attempts. This suggests that age of onset of abuse should be considered along with the type and severity of the abuse when studying the risk for suicidal behaviour in abused populations (51). People who were exposed to CSA, especially women, are at between eight and thirteen times greater risk of suicidal behaviour in adulthood than people who were not exposed to CSA (52). Suicidal ideas and attempted suicide are highly frequent amongst men who were sexually abused in childhood (53).

CSA has a greater effect on the mental health of men (in comparison to women) $(54,55)$. Com- 
pared with women survivors, research seems to indicate that male survivors are particularly at risk of anxiety related symptoms and disorders, and may be particularly susceptible to internalizing effects (56). More specifically, research indicates that male survivors of CSA are at a substantially increased risk for depression, PTSD, personality disorders, poor self-image, substance abuse problems, suicidal tendency, and sexual disorders (57). The response to trauma is probably a mediator, together with various social constructs related to gender, which may cause the differences in psychological reactions to sexual abuse between men and women.

Experience of CSA has been proposed as a major risk factor in the development of eating disorders (EDs) (58-60). Indeed, it appears that CSA victimization may promote dysregulated behavioural control (i.e., impulsivity and compulsivity) as coping strategies for some survivors, which may in turn promote disordered eating behaviours (61). Victims of CSA may develop EDs of various forms and intensities. CSA had the most robust relationship with anorexia nervosa (AN), and this effect was statistically stronger among men compared to women. For bulimia eating disorder (BED), a different trend was noted among men and women. Among women, all child maltreatment types were associated with increased odds of BED, compared to only two child maltreatment types among men (CSA and physical neglect) (60). The empirical evidence suggests that a number of mediators may explain the relationship between CSA victimization and EDs. EDs are often a way to manage trauma in order to reduce suffering, relieve stress and tension, block unwanted feelings and emotions, an attempt to recover shattered self-esteem, eliminate a sense of guilt or deny one's own sexuality, a way to express hatred to one's own body. Many adults with EDs feel guilty about the experience of CSA, believing they could have prevented it, but chose not to because of some defect in themselves (62, 63). Women who were exposed to CSA are dissatisfied with the appearance of their bodies and their body weight, they often go on diets, use cleansing methods, and restrict their dietary intake (64).
A connection was found between CSA and most personality disorders, where the risk is greater for women than for men (65). CSA is connected to the development of borderline personality disorder in adulthood (52), avoidant personality disorder (66) and self-harming (67). Furthermore, short term psychopathological consequences of CSA, according to Ivanov, Platonova and Kozlovskaya (68), are an acute reaction to stress and PTSD.

Interpersonal problems (difficulties in relationships with others, loss of trust, feeling betrayed, fear of sexual partners, and susceptibility to re-victimization) are common long-term consequences of CSA (69). Relationship problems include not only problems with starting a relationship, but also the lack of positive models, learned expectation of abuse, and the feeling that coercion and violence are natural components of a relationship (70). CSA victims have more difficulties in relation to their partner, they get divorced more often, live apart or do not get married at all (71). They do not trust their partners and perceive them as less caring and excessively controlling (72). Furthermore, they are at risk for increased instability in relationships, a higher number of sexual partners, increased risk of sexual problems and greater negativity towards partners (73).

Adults who were sexually abused in childhood may often present various forms of sexual dysfunction $(72,74)$. Sexual problems, such as fear of sexuality, guilt, lack of satisfaction, low sexual desire, low self-esteem as a sexual partner, orgasm problems, compulsive avoidance or compulsive seeking of sexual activity, are common consequences of CSA (75). Professionals and also researchers in empirical and qualitative research mention some gender differences in the long-term consequences of exposure to CSA in men, including undermined masculine identity, confused sexuality, difficulties in partnership relationships, and fear of the perpetrator (76). According to the results of studies conducted to date, CSA is linked to sexual addiction $(77,78)$.

In the period of adolescence and young adulthood, sexual abuse victims are at risk of committing sexual abuse (79). The conclusion from this 
study needs to be interpreted with some care, and we should be aware of the dangers of suggesting that there is a causal relationship between exposure to sexual abuse and sexual offending. Plummer and Cossins (80) undertook a comprehensive literature review of studies of both victims and offenders, including studies that revealed the following: the age of onset of CSA, duration of abuse, the gender of the abuser, the relationship between the victim and the abuser, grooming behaviour, the types and severity of abuse, and disclosure of abuse. They found no evidence for the existence of a cycle of abuse for female CSA victims, but they discovered evidence to support the existence of a cycle of abuse for male CSA victims who had experienced particular abuse characteristics.

Papalia et al. (81) found that those who were CSA survivors were more likely than the control group to engage in all types of criminal behaviours, with specific abuse characteristics, re-victimization, and mental health problems associated with an increased likelihood. The study also found differences by gender, with female survivors more likely to commit general and violent offenses and males more likely to commit sexual offenses. Furthermore, there is an eight-times greater risk that a victim of CSA will physical abuse his or her children (82).

The correlation between CSA and abuse of alcohol and other psychoactive substances in adolescence and adulthood in subjects of both sexes has been established in many studies $(83,84)$. When we discuss consequences of CSA, it is important to take account of a range of individual, family and social factors that might affect or contribute to adverse long-term outcomes. The most significant of these are various aspects of the family environment in which the child was living, including the quality of parenting, parental mental health and possible substance abuse, as well as socio-economic status (parental education and employment), and the possibility that the child was exposed to other forms of abuse and adversity, not sexual abuse alone (85).

\section{Consequences of Childhood Neglect}

Childhood neglect $(\mathrm{CN})$, especially exposure to childhood physical neglect (CPN), leads to de- lays in physical weight or development, without a clearly visible organic cause. These children have poor muscle tone, deformations of the bones of the head and poor hair growth on that part of the head. Furthermore, they more often have rashes and infections. Victims of childhood emotional neglect (CEN) lose weight, despite the fact that their parents meet the child's physical needs (86).

Health problems are twice as likely in children who are neglected in childhood than in children who are not neglected (87). In a prospective investigation of confirmed abuse/neglect cases matched with no abuse controls, Widom, Czaja, Bentley, and Johnson (88) found that individuals who had experienced maltreatment earlier in life were at significantly greater risk for a variety of diseases, including diabetes, lung disease, vision problems, and worse oral health, with significant overlap between these different health outcomes. Research investigating the impact of abuse/neglect on cardiovascular health found associations between self-reported adverse experiences and increased cardiovascular disease in middle adulthood (at age 56 years; 89 ) as well as cardiovascular disease in early adulthood (at mean age 32 years; 90). $\mathrm{CN}$ is linked to frequent liver problems in adulthood (91), asthma and lung cancer (92), the occurrence of migraines (93), and the occurrence of sexually transmitted diseases (94). In retrospective studies, higher levels of reported abuse/neglect, as well as other adverse childhood experiences correlate with poorer self-reported health outcomes in middle adulthood (95).

Children who are neglected develop serious psychological difficulties in the form of different types of anxiety disorder during childhood and/or in adulthood $(6,86)$. Furthermore, neglected children have greater risk for difficulties in emotional development, extreme withdrawal or aggressiveness, anxiety disorders, as well as internalizing and externalizing behaviour problems (96).

On the basis of the review paper by Sesar and Sesar (97) it may be concluded that CPN increases the risk of the occurrence of schizophrenic personality disorder. Supervision neglect increases the risk for the development of passive-aggressive, paranoid 
or borderline personality disorders, and CEN for the development of anti-social personality disorder, borderline personality disorder, obsessive-compulsive disorder and trichotillomania in adolescence and adulthood. The results of this review paper consider the DSM-IV-R, not the current DSM-V diagnostic manual.

Data in this field also indicate that neglected children have greater difficulties in socialization than children who were not neglected. The consequences are already visible in infancy, where children show relatively poorer smiling and babbling behaviours (86). In addition, research has consistently shown that there is a positive correlation between $\mathrm{CN}$ and a tendency to risky and anti-social behaviour in adulthood $(6,94)$.

Neglected children experience delays in cognitive development. Many studies indicate that neglected children have difficulties in linguistic ability in comparison with children who have not been exposed to CN (98). Parents of neglected children most often do not encourage the child's verbal expression, and they do not respond verbally or non-verbally to the child's activities, which has a negative effect on the child's verbal development (99).

\section{Consequences of Witnessing Domestic Violence}

Witnessing domestic violence (WDV), in interaction with individual genetic factors, leads to changes in the development of the brain structures relevant for cognition and regulation of emotions (100), as well as changes in the hormonal system, primarily the hypothalamic-pituitary-adrenal axis (101-104). Adults who witnessed domestic violence in childhood are at risk of developing physical illnesses, such as cardiovascular diseases, hypertension and diabetes (105), and deviations in neurological functioning (106).

Children exposed to domestic violence (DV) over a sustained period may experience trauma symptoms, including PTSD, resulting in psychosocial and physical responses that, if left untreated, may have long lasting effects on the child's development, behaviour and well-being (107). These include psychological difficulties, such as depression, anxiety, insomnia, poor coping mechanisms, suicidal thoughts, eating disorders, anger, self-harm and low self-esteem $(107,108)$.

Anxiety and depression are the most frequent psychological disorders in children, young adults and adults who witnessed domestic violence. Research consistently indicates the stronger expression of anxiety and depression in girls exposed to DV than boys, especially during the period of puberty (109). Younger children are at higher risk of developing anxiety and depression than older children (110). Howell's (111) review of the literature had a particular focus on children of pre-school age. She suggested that exposure to DV for children in this age group raises some particular concerns. Their developmental stage and the fact that they may spend a greater proportion of time with their parents compared to school-age children can affect them whereby they are not able to benefit from the potential buffering effects of exposure to a school environment. Where infants and children cannot rely on parents or caregivers to protect them from or cushion traumatic events, children may instead rely on self-protective behaviours such as withdrawal, anger and aggression, and may have difficulty with developmental tasks due to difficulties in emotional regulation, or have difficulty recognizing emotions in others. In addition, exposure to DV in pre-school-age children may result in physical symptoms too. Frequent exposure to DV is an independent risk factor for depressive symptoms in young adulthood (112).

Sustained and chronic exposure to DV can result in trauma that may distort survivors' sense of identity and concept of others, leading to mistrust, social isolation and the inability to relate to others $(108,113)$. The results of research into the effects of WDV on social functioning show that children who have experienced DV, due to the learned forms of violent behaviour, are more aggressive or withdrawn in peer relationships, whereby their abilities to initiate and maintain good quality reciprocal 
social interaction are limited (114). In this group of children, there are relatively more frequent difficulties in finding ways to resolve conflicts in relationships or problems, and they are more prone to aggressive, delinquent and/or antisocial behaviour than children who were not witnesses of domestic violence (115).

Caregivers who are chronically unavailable to young children increase their risk of having stressful experiences in their lives, difficulty in attachment and being able to self-sooth to deal with stressful times $(72,116)$. Infants who experience continuous stress are more likely to be highly sensitive and do not learn self-soothing behaviour as they develop (116). Children who experience abusive or unattached caregiving are likely to develop negative reactions to their caregiver, due to the absence of attachment or increased anger, and this may cause negative reactions towards themselves (117). Children with insecure attachment may be avoidant towards their caregivers, or ambivalent, by being withdrawn or avoidant (116).

Further, one of the most significant consequences of WDV in childhood is violent behaviour in intimate relationships (114, 118). Mounting evidence links exposure to DV and perpetration of teen dating violence (119). Research shows that WDV as a boy can be related to men's perpetration of DV (120). Many female victims of DV come from homes where they witness DV between their parents. Learning theory would explain that boys "learn" how to become abusers and girls "learn" about victimization (121).

As expected, the results of most studies show that children who witness DV have poorer cognitive abilities (100) than children who have not witnessed DV. Difficulties in cognitive function in children who have been exposed to DV are frequently linked to difficulties and poor functioning in the academic environment $(23,115)$.

\section{Consequences of Multi-Type Childhood Abuse}

Trauma seems to be particularly pertinent for children who have experienced multi-type forms of childhood abuse (113). The co-occurrence of domestic and family violence with other forms of childhood abuse, including physical, emotional and sexual abuse, is well established in international research $(113,122,123)$. The multiple stresses to which children are exposed through various forms of abuse and neglect, combine and accumulate in various ways, and as a result, the consequences of multi-type childhood abuse are more serious, less reversible, and hard to differentiate (113). Longterm exposure to multi-type childhood abuse is thought to result in what has been described as "cumulative harm", which has similar effects to trauma, but with more specific outcomes for children's development and behaviour (113).

Exposure to various forms of childhood abuse and neglect result in the development of serious psychological problems (113). People exposed to multi-type childhood abuse, according to research undertaken so far (124), are more prone to suicide in comparison with people who were not abused, where no differences were found in relation to the sex of the subjects.

Persons exposed to multi-type childhood abuse (124) have a significantly higher risk of smoking, and consuming alcohol and other psychoactive substances. The cumulative effect of the experience of multi-type childhood abuse is also linked to a higher frequency of risky behaviour (125). Young people exposed to multi-type childhood abuse are more prone to break rules at school, aggressive behaviour, and antisocial and asocial behaviour $(124,126)$. The scope and severity of behavioural problems are proportional to the duration of the abuse. The earlier a child was exposed to abuse, the greater the probability of behavioural problems in adolescence (13). Aggressive behaviour towards oneself and others, self-hatred, lack of awareness of danger, irritability, impulsiveness, delinquency and violent behaviour, rule-breaking, and other forms of auto-destructive behaviour are often found in children exposed to abuse $(113,127)$. Furthermore, they have disturbed attachment behaviours. According to the results of a major national study conducted in the USA, children exposed to abuse 
in various periods of life (infancy, early and middle childhood) have more behavioural problems than children exposed to abuse in only one of these periods (128). Adolescents exposed to multi-type childhood abuse are at greater risk of unwanted pregnancy and promiscuous behaviour (124).

PTSD is one of the most frequent indirect consequences of childhood abuse (129). PTSD in children who have experienced multi-type childhood abuse is characterized by symptoms such as persistent re-experiencing of the traumatic events related to the abuse; avoiding people, places, and events that are associated with abuse; feeling fear, horror, anger, guilt, or shame; startling easily; and exhibiting hyper-vigilance, irritability, or other changes in mood (130). Recent insights in this field indicate the complexity of the developmental consequences for a child exposed to abuse, and it is believed that the term PTSD does not cover all the symptomology. Therefore the term "complex trauma" has been proposed (113).

Young people who experienced multi-type childhood abuse were found to be 3.7 times more likely than those who were not abused to be depressed at 23-24 years, and 2.7 times more likely to be anxious (113). Panic disorder, general anxiety disorder and depressive disorder are frequent shortterm and long-term consequences of exposure to multi-type childhood abuse (39-41).

Childhood multi-type abuse has been linked to a higher risk for a wide range of long-term and/or future health problems $(88,113,131,132)$. Exposure to abuse and neglect in children results in structural and functional changes to various parts of the nervous system (25). Victims of CSA and CPA have higher risk for respiratory and gastrointestinal problems in adulthood and visit the doctor more often (133). According to the results of Rohde et al. (134) both forms of abuse predicted greater obesity in adulthood. Victims of CSA and CPA in adulthood have more expressed traumatic symptoms (133). Young people who are exposed to a combination of $\mathrm{CPA}$, CSA and CN have serious consequences, according to Moran, Vuchinich and Hall (18).
CEA in combination with other forms of childhood abuse was the most significant predictor of difficulties in psychological adjustment in adolescence (135). Exposure to CEA in combination with CPA and/or CSA or WDV is strongly connected with difficulties in psychological adjustment, manifesting through aggressive and rule-breaking behaviour, somatic complains, social problems, and external psychological difficulties in adolescence (135). CEA, CSA, and CPA are associated with violent behaviour in dating relationships (21).

\section{Conclusion}

Childhood abuse and neglect are linked to many negative consequences in various areas of the functioning of children, such as cognitive, physical, psychological, behavioural and social functioning. Moreover, research to date has shown that abuse, as well as immediate consequences, also has clearly documented consequences which extent into adulthood and affect physical, psychological and social functioning, and contribute to the development of psychopathological disorders in adulthood. However, no definite causal connection between difficulties and abuse can be established, since many individual and environmental factors may have a mediating role in the relationship between the traumatic experiences of childhood abuse and neglect, and the consequences of childhood abuse and neglect. It is also necessary, when drawing conclusions about the consequences of childhood abuse and neglect, to take into account the methodology of the research, reflected in the different samples of subjects participating in the research, as well as the different techniques and measuring instruments used in studying childhood abuse and neglect and its negative outcomes. Future research in this area needs to focus on disentangling the effects of childhood abuse and neglect from those of other conditions. There is a need to explore beneath the surface to understand the behavioural, neurobiological, social, and environmental mechanisms that mediate the association between exposure to childhood abuse and neglect, and their behavioural and 
neurobiological sequelae. Assessment of children presenting for evaluation of problems related to childhood abuse and neglect is necessarily complex and likely requires a multi-disciplinary approach and more time than evaluations of non-abused children. Treatment of symptoms and disorders related to childhood abuse and neglect should also be multi-disciplinary, and often needs to address external factors that may contribute to their perpetuation and exacerbation.

However, communities can act to stem the effects of childhood abuse and neglect and even prevent it. Evidence-based services and support can promote protective factors that mitigate the effects of childhood abuse and neglect, as well as providing families and communities with the tools they need to stop it before it occurs. Child welfare agencies can work with families and communities to spearhead initiatives that build upon strengths and address needs.

Conflict of Interest: The authors declare that they have no conflict of interest.

\section{References}

1. World Health Organization. World Report on Violence and Health. Geneva: Switzerland; 2002.

2. Levendosky AA, Bogat GA, Martinez-Torteya C. PTSD symptoms in young children exposed to intimate partner violence. Violence Against Wom. 2013;19(2):187-201.

3. Streeck-Fischer A, van der Kolk BA. Down will come baby, cradle and all: Diagnostic and therapeutic implications of chronic trauma on child development. Aust NZ J Psychiat. 2000;34(6):903-18.

4. Franke HA. Toxic stress: Effects, Prevention and Treatment. Children (Basel). 2014;1(3):390-402.

5. Springer K, Sheridan J, Kuo D, Carnes M. Long-term physical and mental health consequences of childhood physical abuse: Results from a large population-based sample of men and women. Child Abuse Negl. 2017;31:51730 .

6. Norman RE, Byambaa M, Butchart A, Scott J, Vos T. The long-term health consequences of child physical abuse, emotional abuse, and neglect: A systematic review and meta-anallysis. PLoS Medicine. 2012;9(11):e1001349.
7. Teicher MH, Anderson CM, Ohashi K, Polcari A. Childhood maltreatment: Altered network centrality of cingulate, precuneus, temporal pole and insula. Biol Psychiatry. 2014;76(4):297-305.

8. De Bellis MD, Zisk A. The Biological Effects of Childhood Trauma. Child Adolesc Psychiatr Clin N Am. 2014;23:185-222.

9. Rosen AL, Handley ED, Cicchetti D, Rogosch FC. The impact of patterns of trauma exposure among low-income children with and without histories of child maltreatment. Child Abuse Negl. 2018;80:301-11.

10. McKissick S. Effects of Childhood Trauma on Neurological Development and Mental, Physical Health in Adulthood. D.U. Quark. 2019:3(2). Available from: https://dsc. duq.edu/duquark/vol3/iss $2 / 7$

11. Nemeroff CB. Paradise lost: The neurobiological and clinical consequences of child abuse and neglect. Neuron. 2016;89(5):892-909.

12. Parr JR, Jayawant S. Childhood myasthenia: clinical subtypes and practical management. Dev Med Child Neurol. 2007;49(8):629-35.

13. Frederico M, Jackson A, Black C. Understanding the impact of abuse and neglect on children and young people referred to a therapeutic program. J Fam Stud. 2008;14(23):342-61.

14. Thompson R, Proctor LJ, English DJ, Dubowitz H, Narasimhan S, Everson MD. Suicidal ideation in adolescence: Examining the role of recent adverse experiences. J Adolescence. 2012;35(1):175-86.

15. McFarlane JM, Groff JY, O'Brien JA, Watson K. Behaviors of children who are exposed and not exposed to intimate partner violence: an analysis of 330 black, white, and Hispanic children. Pediatrics. 2003;112(3):e202-7.

16. Cyr C, Euser EM, Bakermans-Kranenburg MJ, Van Ijzendoorn MH. Attachment security and disorganization in maltreating and high-risk families: A series of meta-analyses. Dev Psychopathol. 2010;22(1):87-108.

17. Trickett PK, Negriff S, Ji J, Peckins M. Child maltreatment and adolescent development. J Res Adolescence. 2011;21(1):3-20.

18. Moran P, Vuchinich S, Hall N. Associations between types of maltreatment and substance use during adolescence. Child Abuse Negl. 2004;28(5):565-74.

19. Hussey J, Chang J, Kotch J. Child maltreatment in the United States: Prevalence, risk factors, and adolescent health consequences. Pediatrics. 2006;118(3):933-42.

20. Maas C, Herrenkohl T, Sousa C. Review of research on child maltreatment and violence in youth. Trauma Violence Abus. 2008;9(1):56-67. 
21. Verrill A. The Relationship between Childhood Abuse and Aggressive Behavior in Adulthood. JIUR [serial on the Internet]. 2018 [cited 2019 Sep 20];10(2):[about 16 p.]. Available from: https://knowledge.e.southern.edu/jiur/ vol10/iss $1 / 2$

22. Murphy N. Maltreatment of children with disabilities: The breaking point. J Child Neurol. 2011;26:1054-6.

23. Gilbert R, Spatz Widom C, Browne K, Fergusson $\mathrm{D}$, Webb E, Janson J. Burden and consequences of child maltreatment in high-income countries. Lancet. 2009;373(9657):68-81.

24. Morton PM, Mustillo SA, Ferraro KF. Does childhood misfortune raise the risk of acute myocardial infarction in adulthood? Soc Sci Med. 2014;104:133-41.

25. Dodaj A, Sesar K, Šimić N. The neurobiological aspects of exposure to childhood maltreatment. In: Costa A, Villalb E, editors. Horizons in Neuroscience Research. New York: Nova Science Publishers; 2018. p.81-108.

26. Christ C, de Waal MM, Dekker JJM, van Kuijk I, van Schaik DJF, Kikkert MJ, et al. Linking childhood emotional abuse and depressive symptoms: The role of emotion dysregulation and interpersonal problems. PLoS One. 2019;14(2):e0211882.

27. Jeon HJ, Roh MS, Kim KH, Lee JR, Lee D, Yoon SC, et al. Early trauma and lifetime suicidal behavior in a nationwide sample of Korean medical students. J Affect Disorders. 2009;119(1-3):210-4.

28. McLaughlin KA, Green JG, Grukber MJ, Sampson NA, Zaslavsky AM, Kessler RC. Childhood adversities and first onset of psychiatric disorders in a national sample of US adolescents. Arch General Psychiatry. 2012;69(11):115160.

29. Spinazzola J, Hodgdon H, Liang LJ, Ford JD, Layne CM, Pynoos R, et al. Unseen wounds: The contribution of psychological maltreatment to child and adolescent mental health and risk outcomes. Psychol Trauma. 2014;6(1):1828.

30. Layne CM, Briggs-King E, Courtois C. Introduction to the Special Section: Unpacking risk factor caravans across development: Findings from the NCTSN Core Data Set. Psychol Trauma. 2014;6(1):1-8.

31. Trickett PK, Kim K, Prindle J. Variations in emotional abuse experiences among multiply maltreated young adolescents and relations with developmental outcomes. Child Abuse Negl. 2011;35:876-86.

32. Groleau P, Steiger H, Bruce K, Israel M, Sycz I, Badawi G. Childhood emotional abuse and eating symptoms in bulimic disorders: An examination of possible mediating variables. Int J Eat Disorder. 2012;45(3):326-32.
33. Dvir Y, Ford JD, Hill M, Frazier JA. Childhood maltreatment, emotional dysregulation, and psychiatric comorbidities. Harvard Rev Psychiatry. 2014;22(3):149-61.

34. Hailes HP, Yu R, Danese A, Fazel S. Long-term outcomes of childhood sexual abuse: an umbrella review. Lancet Psychiatry. 2019;6(10):830-9.

35. Hinchliffe J. Child abuse issues. Br Dent J. 2011;210:4238.

36. Irish L, Kobayashi I, Delahanty DL. Long-term physical health consequences of childhood sexual abuse: a metaanalytic review. J Pediatr Psychol. 2010;35:450-61.

37. Wilson DR. Helath Consequences of Childhood Sexual Abuse. Perspect Psychiatr C. 2010;46(1):56-64.

38. Liebschutz JM, Feinman G, Sullivan L, Samet J. Physical and sexual abuse in women infected with the human immunodeficiency virus: increased illness and health care utilization. Arch Intern Med. 2000;160(11):1659-64.

39. Amado BG Arce R Herraiz. A Psychological injury in victims of child sexual abuse: a meta-analytic review. Psychosoc Interv. 2015;24:49-62.

40. Chen LP, Murad MH, Paras ML, Colbenson KM, Sattler AL, Goranson EN, et al. Sexual abuse and lifetime diagnosis of psychiatric disorders: systematic review and metaanalysis. Mayo Clin Proc. 2010;85:618-29.

41. Varese F, Smeets F, Drukker M, Lieverse R, Lataster T, Viechtbauer W, et al. Childhood adversities increase the risk of psychosis: a meta-analysis of patient-control, prospective- and cross-sectional cohort studies. Schizophr Bull. 2012;38:661-71.

42. Shrivastava AK, Karia SB, Sonavane SS, De Sousa AA. Child sexual abuse and the development of psychiatric disorders: a neurobiological trajectory of pathogenesis. Ind Psychiatry J. 2017;26(1):4-12.

43. Briere J, Elliott DM. Prevalence and psychological sequelae of selfreported childhood physical and sexual abuse in a general population sample of men and women. Child Abuse Negl. 2003;27(10):1205-22.

44. Fergusson DM, Swain-Campbell NR, Horwood LJ. Does sexual violence contribute to elevated rates of anxiety and depression in females? Psychol Med. 2002;32(6):991-6.

45. Salter M, Breckenridge J. Women, trauma and substance abuse: understanding the experiences of female survivors of childhood abuse in alcohol and drug treatment. Int J Soc Welf. 2014;23(2):165-73.

46. Williams LM, Debattista C, Duchemin AM, Schatzberg AF, Nemeroff CB. Childhood trauma predicts antidepressant response in adults with major depression: data from the randomized international study to predict optimized treatment for depression. Transl Psychiatry. 2016;6:e799. 
47. Devries KM, Mak JY, Child JC, Falder G, Bacchus LJ, Astbury J, et al. Childhood sexual abuse and sucidal behavior: A meta - analysis. Pediatrics. 2014;133(5):e133144.

48. Angelakis I, Gillespie EL, Panagioti M. Childhood maltreatment and adult suicidality: a comprehensive systematic review with meta-analysis. Psychol Med. 2019;49(7):1057-78.

49. Wherry JN, Corson K, Hunsaker S. A short form of the Trauma Symptom Checklist for Young Children. Assessment of Childhood Sexual Abuse and Trauma. 2013;22(7): 796-821.

50. Pérez-González A, Pereda N. Systematic review of the prevalence of suicidal ideation and behavior in minors who have been sexually abused. Systematic review of the prevalence of suicidal ideation and behavior in minors who have been sexually abused. Actas Esp Psiquiatr. 2015;43(4):14958.

51. Lopez-Castroman J, Melhem N, Birmaher B, Greenhill L, Kolko D, Stanley B, et al. Early childhood sexual abuse increases suicidal intent. World Psychiatry. 2013;12(2):14954.

52. Brodsky BS, Oquendo M, Ellis SP, Haas GL, Malone KM, Mann JJ. The relationship of childhood abuse to impulsivity and suicid behavior in adult with major depression. Am J Psychiat. 2001;159(11):1871-7.

53. Easton SD, Renner LM, O'Leary PJ. Suicide attempts among men with histories of child sexual abuse: Examining abuse severity, mental health, and masculine norms. Child Abuse Negl. 2013;37(6):380-7.

54. Jonas S, Bebbington P, McManus S, Meltzer H, Jenkins R, Kuipers E, et al. Sexual abuse and psychiatric disorder in England: results from the 2007. Adult Psychiatric Morbidity Survey. Psychol Med. 2011;41(4):709-20.

55. Schraufnagel TJ, Davis KC, George WH, Norris J. Childhood sexual abuse in males and subsequent risky sexual behavior: A potential alcohol-use pathway. Child Abuse Negl. 2010;34(5):369-78.

56. Dorahy MJ, Clearwater K. Shame and Guilt in Men Exposed to Childhood Sexual Abuse: A Qualitative Investigation. J Child Sex Abus. 2012;21(2):155-75.

57. Romano E, De Luca RV. Characteristics of perpetrators with histories of sexual abuse. Int J Offender Th. 196; $40: 147-56$.

58. Paraventi F, Claudino AM, Morgan CM, Jair de Jesus M. A case-control study to assess the impact of childhood sexual abuse on eating disorders. Rev Psiquiatr Clín. 2011;38(6):222-6.
59. Micali N, Martini MG, Thomas JJ, Eddy KT, Kothari R, Russell E, et al. Lifetime and 12-month prevalence of eating disorders amongst women in mid-life: a populationbased study of diagnoses and risk factors. BMC Medicine. 2017;15(1):12.

60. Afifi TO, Sareen J, Fortier J, Taillieu T, Turner S, Cheung $\mathrm{K}$, et al. Child maltreatment and eating disorders among men and women in adulthood: Results from a nationally representative United States sample. Int J Eat Disord. 2017;50:1281-96.

61. Dworkin E, Javdani S, Verona E, Campbell R. Child sexual abuse and disordered eating: The mediating role of impulsive and compulsive tendencies. Psychol Violence. 2014;4(1):21-36.

62. Opydo-Szymaczek J, Jarząbek-Bielecka G, Kędzia W, Borysewicz-Lewicka M. Child sexual abuse as an etiological factor of overweight and eating disorders - considerations for primary health care providers. Ginekol Pol. 2018;89:48-54

63. Jarząbek-Bielecka G, Mizgier M, Kędzia W. Child Sexual Abuse and Eating Disorders. Austin J Obstet Gynecol. 2018;5(8):1124.

64. Wonderlich SA, Crosby RD, Mitchell JE, Roberts JA, Haseltine B, Demuth G, et al. Relationship of Childhood Sexual Abuse and Eating Disturbance in Children. J Am Acad Child Psy. 2000;39(10):1277-83.

65. Jumaian A. Prevalence and long-term impact of child sexual abuse among sample of male college students in Jordan. E Mediterr Health J. 2001;7(3):435-40.

66. Pope HGJr, Mangweth B, Negrao AB, Hudson AB, Cordas TA. Childhood sexual abuse and bulimia nervosa: a comparison of American, Austrian, and Brazilian women. Am J Psychiat. 1994;151(5):732-7.

67. Romans SE, Martin JL, Anderson JC, Herbison GP, Mullen PE. Sexual abuse in childhood and deliberate selfharm. Am J Psychiat. 1995;152(9):1336-42.

68. Ivanov M, Platonova N, Kozlovskaya G. Long-term Mental Health Consequences of Child Sexual Abuse. Eur Psychiat. 2015;30(1):28-31.

69. Lamoureux BE, Palmieri PA, Jackson AP, Hobfoll SE. Child sexual abuse and adulthood-interpersonal outcomes: Examining pathways for intervention. Psychol Trauma. 2012;4:605-13.

70. Włodarczyk J. Childhood sexual abuse and its effects in adult life. Executive summary. Warsaw: Empowering Children Foundation;2016.

71. Bifulco A, Brown GW, Adler Z. Early sexual abuse and clinical depression an adult life. Brit J Psychiat. 1991;159:115-22. 
72. Howell K, Barnes S, Miller L, Graham-Bermann S. Development variations in the impact of intimate partner violence exposure during childhood. J Int Violence Res. 2016;8(1):43-57.

73. Hsu ET. Child sexual abuse, interpersonal difficulties, and staying in relationships with intimate partner violence: a preliminary study". Syracuse University. Dissertations. 2016. Available from https://surface.syr.edu/etd

74. Mullen PE, Martin JL, Anderson JC, Romans SE, Herbison GP. The long-term impact of the physical, emotional, and sexual abuse of children: a community study. Child Abuse Negl.1996;20(1):7-21.

75. Beisert M, Izdebska A. Wykorzystanie seksualne dzieci. Dziecko krzywdzone. 2012;2:48-66.

76. Easton SD, Saltzman L, Willis D. Would you tell under circumstances like that? Barriers to disclosure for men who were sexually abused during childhood. Psychol Men Masculin. 2014;15:460-9.

77. Perera B, Reece M, Monahan P, Billingham R, Finn P. Childhood characteristics and personal dispositions to sexually compulsive behavior among young adults. Sex Addict Compulsivity. 2009;16(2):131-45.

78. Aaron M. The pathways of problematic sexual behavior: A literature review of factors affecting adult sexual behavior in survivors of childhood sexual abuse. Sex Addict Compulsivity. 2012;19(3):199-218.

79. Freeman RC, Collier K, Parillo KM. Early life sexual abuse as a risk factor for crack cocaine use in sample of community-recruited women at high risk for illicit drug use. The Am J Drug Alcohol Ab. 2002;28(1):109-31.

80. Plummer M, Cossins A. The Cycle of Abuse: When Victims Become Offenders. Trauma Violence Abuse. 2018;19(3):286-304.

81. Papalia N, Ogloff JR, Cutajar M, Mullen P. Child Sexual Abuse and Criminal Offending: Gender-Specific Effects and the Role of Abuse Characteristics and Other Adverse Outcomes. Child Maltreatment. 2018;23(4):1-18.

82. Hall LA, Sachs B, Rayens MK. Mothers' potential for child abuse: the roles of childhood abuse and social resources. Nurs Res. 1998;47(2):87-95.

83. Salter M, Breckenridge J. Women, trauma and substance abuse: Understanding the experiences of female survivors of childhood abuse in alcohol and drug treatment. Int J Soc Welf. 2014;23(2):165-73.

84. Tonmyr L, Shields M. Childhood sexual abuse and substance abuse: A Gender paradox? Child Abuse Negl. 2017;63:284-94.

85. Noll JG. Sexual abuse of children - Unique in its effects on development? Child Abuse Negl. 2008;32(6):603-5.
86. McCoy ML, Keen SM. Child abuse and neglect. 2nd ed. New York, NY: Psychology Press; 2013.

87. Davidson-Arad B, Benbenishty R, Chen W, Glasser S, Zur S, Lerner-Geva L. Distinguishing neglect from abuse and accident: Analysis of the case files of a hospital child protection team in Israel. Health Soc Care Community. 2010;18(6):614-23.

88. Widom CS, Czaja SJ, Bentley T, Johnson MS. A prospective investigation of physical health outcomes in abused and neglected children: New findings from a 30-year follow up. Am J Public Health. 2012;102:1135-44.

89. Anda RF, Brown DW, Dube SR, Bremner JD, Felitti VJ, Giles WH. Adverse childhood experiences and chronic obstructive pulmonary disease in adult. Am J Prev Med. 2008;34:396-403.

90. Batten SV, Aslan M, Maciejewski PK, Mazure CM. Childhood maltreatment as a risk factor for adult cardiovascular disease and depression. J Clin Psychiat. 2004;65:249-54.

91. Dong M, Dube SR, Felitti VJ, Giles HP, Anda RF. Adverse childhood experiences and self-reported liver disease: New inshights into a causal pathway. Arch Intern Med. 2003;163(16):1949-56.

92. Brown DW, Young KE, Anda RF, Felitti VJ, Giles HP. Asthma and the risk of lung cancer. Findings from the adverse childhood epxeriences. Cancer Cause Control. 2006;17(3):349-50.

93. Tietjen GE, Brandes JL, Peterlin BL, Eloff A, Dafer RM, Stein MR, et al. Childhood maltreatment and migraine (part 1). Prevalence and adult revictimization: A multicenter headache clinic study. Headache. 2009;10(1):2030.

94. Hayden AA, Hussey JM, Halpern CT. Childhood abuse and neglect and the risk of STDs in early adulthood. Perspect Sex Reprod Health. 2011;43(1):16-22.

95. Min MO, Singer LT, Minnes S, Kim H, Short E. Mediating links between maternal childhood trauma and preadolescent behavioral adjustment. J Interpers Violence. 2013;28(4):831-51.

96. Antle B, Barbee A, Yankeelov P, Bledsoe L. A qualitative evaluation of the effects of mandatory reporting of domestic violence on victims and their children. J Fam Soc Work. 2010;13:56-73.

97. Sesar K, Sesar D. Emotional abuse of children. Paediatria Croatica, 2008;53(2):93-98.

98. Crosson-Tower C. Understanding child abuse and neglect. Needham Heights: Allyn and Bacon; 2005.

99. Dodaj A, Krajina M, Sesar K, Šimić N. The effects of maltreatment in childhood on working memory capacity in adulthood. Eur J Psychol. 2017;13(4):618-32. 
100. Devaney J. Research review: The impact of domestic violence on children. Irish Probation Journal. 2015;12:79-94.

101. Danese A, McEwen BS. Adverse childhood experiences, allostasis, allostatic load, and age-related disease. Physiol Behav. 2012;106:29-39.

102. McEwen BS. Brain on stress: How the social environment gets under the skin. PNAS. 2012;109(2):17180-5.

103. 1 De Bellis MD, Zisk A. The Biological Effects of Childhood Trauma. Child Adolesc Psychiatr Clin N Am. 2014;23:185-222.

104. Tsavoussis A, Stawicki SP, Stoicea N, Papadimos TJ. Child-witnessed domestic violence and its adverse effects on brain development: a call for societal self-examination and awareness. Front Public Health. 2014;10(2):178.

105. Schnurr M, Lohman B. Long-term effects of exposure to abuse during childhood: Longitudinal impact of toddlers' exposure to domestic violence. J Aggress Maltreat T. 2013;22(9):1015-31.

106. Siegel D. Mindsight: The new science of personal transformation. 1st ed. New York: Bantam Book; 2010

107. Jaffe P, Wolfe DA, Campbell M. Advances in psychotherapy-Evidence-based practice: Vol. 23. Growing up with domestic violence: Assessment, intervention, and prevention strategies for children and adolescents. Hogrefe Publishing;2012.

108. Knight C. Trauma-informed social work practice: Practice considerations and challenges. Clin Social Work J. 2015;43:25-37.

109. Meltzer H, Doos L, Vostanis P, Ford T, Goodman R. The mental health of children who witness domestic violence. Child Fam Soc Work. 2009;14(4):491-501.

110. Finkelhor D, Hamby SL, Ormrod R, Turner H. The Juvenile Victimization Questionnaire: Reliability, validity, and national norms. Child Abuse Negl. 2005;29(4):383-412.

111. Howell KH. Resilience and psychopathology in children exposed to family violence. Aggress Violent Behav. 2011;16(6):562-9.

112. Russell D, Springer KW, Greenfield EA. Witnessing domestic abuse in childhood as an independent risk factor for depressive symptoms in young adulthood. Child Abuse Negl. 2010;34(6):448-53.

113. Price-Robertson R, Higgins D, Vassallo S. Multi-type maltreatment and polyvictimisation: A comparison of two research frameworks. Family Matters. 2013;93:8498.

114. Gaudin JMJr, Polansky NA, Kilpatrick AC, Shilton P. (1993). Loneliness, depression, stress, and social supports in neglectful families. Am J Orthopsychiat. 1993;63(4):597-605.
115. Gowan J. Effects of neglect on the early development of children: Final report. Washington, DC: National Clearinghouse on Child Abuse and Neglect, National Center on Child Abuse and Neglect, Administration for Children \& Families; 1993.

116. Herman-Smith R. Intimate partner violence exposure in early childhood: an ecobiodevelopmental perspective. Health Soc Work. 2013;38(4):231-9.

117. Waldman-Levi A, Finzi-Dottan R, Weintraub N. Attachment security and parental perception of competency among abused women in the shadow of PTSD and childhood exposure to domestic violence. J. Child Fam Stud. 2013;24:57-65.

118. Nixon K, Cripps K. Child protection policy and Indigenous intimate partner violence: Whose failure to protect? In. S. Strega, J. Krane, S. Lapierre, and C. Richardson (Eds.), Failure to protect: Moving beyond gendered responses (p. 166-88). Halifax, NS: Fernwood.2013

119. Temple JR, Shorey RC, Fite PJ, Stuart GL, Le VD. Substance use as a longitudinal predictor of the perpetration of teen dating violence. J Youth Adolesc. 2013;42:596606.

120. Payne B, Triplett RA. Assessing the Domestic Violence Training Needs of Benefits Workers. J Fam Violence. 24(4):243-53.

121. Payne BK, Gainey RR. Family violence and criminal justice: A life-course approach (3rd ed.). Anderson Publishing Co;2009.

122. Bromfield LM, Lamont A, Parker R, Horsfall B. Issues for the safety and wellbeing of children in families with multiple and complex problems: the co-occurrence of domestic violence, parental substance misuse, and mental health problems 2010 (NCPC Issues No. 33). Available from <www.aifs.gov.au/nch/pubs/issues/ issues33/issues33.html>

123. Goddard C, Bedi G. Intimate Partner Violence and Child Abuse: A Child-Centred Perspective. Child Abuse Rev. 19(1):5-20.

124. Mangion M, Buttigieg SC. Multi-type childhood maltreatment: Associations with health risk behaviours and mental health problems in adolescence. J Child Serv. 2014;3:191-206.

125. Annerbäck EM, Sahlqvist L, Svedin CG, Wingren G, Gustafsson PA. Child physical abuse and concurrence of other types of child abuse in Sweden-associations with health and risk behaviors. Child Abuse Negl. 2012;36(78):585-595.

126. Chan KL, Brownridge DA, Yan E, Fong DY, Tiwari A. Child maltreatment polyvictimization: Rates and short- 
term effects on adjustment in a representative Hong Kong sample. Psychol Violence. 2011;(1):4-15.

127. Moylan CA, Herrenkohl TI, Sousa C, Tajima EA, Herrenkohl RC, Russo $\mathrm{M} \mathrm{J}$. The effects of child abuse and exposure to domestic violence on adolescent internalizing and externalizing behaviour problems. J Fam Violence. 2010;25(1):53-63.

128. Jaffee SR, Maikovich-Fong AK. Effects of chronic maltreatment and maltreatment timing on children's behavior and cognitive abilities. J Child Psychol Psyc. 2011;52(2):184-94.

129. Telman MD, Overbeek MM, de Schipper JC, LamersWinkelman F, Finkenauer C, Schuengel C. Family Functioning and Children's Post-Traumatic Stress Symptoms in a Referred Sample Exposed to Interparental Violence. J Fam Violence. 2016;31:127-136.

130. Sege RD, Amaya-Jackson L, et al. Clinical Considerations Related to the Behavioral Manifestations of Child Maltreatment. Pediatrics. 2017;139(4):e20170100
131. Monnat SM, Chandler RF. Long-term physical health consequences of adverse childhood experiences. The Sociological Quarterly. 2015;56:723-52.

132. Afifi TO, MacMillan HL, Boyle M, Cheung K, Taillieu T, Turner S, Sareen J. Child abuse and physical health in adulthood. Health Reports. 2016;27:10-8.

133. Higgins DJ, McCabe MP. Multi-Type Maltreatment and the Long-Term Adjustment of Adults. Child Abuse Rev. 2000;9(1):6-18.

134. Rohde P, Ichikawa L, Simon GE, Ludman EJ, Linde JA, Jeffery RW, et al. Associations of child sexual and physical abuse with obesity and depression in middle-aged women. Child Abuse Negl. 2008;32(9):878-87.

135. Sesar K, Živčić - Bećirević I, Sesar D. Multitype Maltreatment in Childhood and Psychological Adjustment in Adolescence: Questionnaire Study. CMJ. 2008;49:2432-58. 